\title{
Pulmonary Infection due to Mycobacterium xenopi
}

\author{
Takeshi Terashima, Fumio Sakamaki, Naoki Hasegawa, Minoru Kanazawa and Takeo Kawashiro
}

\begin{abstract}
We describe two cases of pulmonary infection due to Mycobacterium xenopi (M. xenopi). Both cases were men, ages 61 and $54 \mathrm{yr}$. In the first patient, lung infection due to $M$. xenopi occurred after gastrectomy. The second patient had an inactive $M$. tuberculosis infection. Both had pulmonary symptoms including cough, sputum and fever. Each chest $X$-ray showed an infiltrative shadow with a cavity in a unilateral, upper lobe. Isolates from both patients were studied not only by microbiological characteristics but also by DNA-DNA hybridization. All isolates were susceptible to streptomycin and kanamycin. In the first case, the patient had initially received rifampicin, isoniazid and ethambutol despite in vitro susceptibility patterns, however, there was no response and a new infiltrative shadow appeared in the contralateral lobe. With a multiple drug regimen based on in vitro susceptibility, clinical and roentgenographic improvements were achieved. The second patient showed a favorable response to the initial chemotherapy. Pulmonary infection due to $M$. xenopi can generally be successfully treated with drugs to which the organisms show in vitro sensitivity. We also reviewed the other two cases reported in Japan.

(Internal Medicine 33: 536-539, 1994)
\end{abstract}

Key words: clinical manifestation, drug sensitivity, DNA-DNA hybridization

\section{Introduction}

Mycobacterium xenopi (M. xenopi) was first described by Schwabacher in 1959 (1). Since then, this organism has been isolated both as an environmental contaminant, particularly from hot water systems, and as a presumed etiologic agent of human disease $(2-4)$. The prevalence of $M$. xenopi varies geographically, being one of the most commonly isolated nontuberculous mycobacteria in France (5), England (6, 7) and Canada (8), and less commonly identified in the USA (9) and Sweden (10). In Japan, few cases have appeared in the literature since the first case of lung infection due to $M$. xenopi was reported in $1984(11,12)$. We review 4 cases of pulmonary infection due to $M$. xenopi in Japan, including two patients in our hospital whose isolates were identified not only by conventional microbiological methods but also by the DNA-DNA hybridization (DDH) method (13).

\section{Methods}

In reviewing the 4 cases of $M$.xenopi infection in Japan, we sought the following information: age, sex, pre-existing disease, clinical manifestations, radiological findings, antibiotic susceptibility, treatment and outcome. Identification of the organism was performed by microbiological characteristics (1) and a rapid genetic technique. Sensitivity testing was performed by the standard techniques used in our laboratory.

Genetic identification was performed by the DDH method using DDH mycobacteria Kyokuto (Kyokuto Pharmaceutical Co. Tokyo). One-half a loopful of mycobacterial cells (approximately $3 \mathrm{~mm}^{3}$ ) growing in a culture was harvested and transferred to a test tube. According to a previously reported method (13), DNAs from clinical strains were precipitated and labeled with photobiotin. Labeled single-stranded DNA was hybridized to reference DNAs immobilized on microdilution plate wells. The extent of hybridization was determined by colorimetric measurement using a microplate reader (Auto Reader II; Sanko Junyaku Co. Tokyo).

Diagnostic criteria are necessary to distinguish patients with active disease from those in whom $M$. xenopi is a casual contaminant and hence of no clinical significance. M. xenopi was considered to be a pathogen and a cause of disease in patients when the findings satisfied the following criteria for disease caused by nontuberculous mycobacteria: 1) repeat positive cultures of the same organism from sputum or gastric juice over a period of weeks to months, 2) presence of clinical symptoms and abnormal radiographic appearances that are not otherwise explainable $(8,14)$.

From the Department of Medicine, School of Medicine, Keio University, 35 Shinanomachi, Shinjuku-ku, Tokyo

Received for publication March 2, 1994; Accepted for publication June 24, 1994

Reprint requests should be addressed to Dr. Takeshi Terashima, the Department of Medicine, School of Medicine, Keio University, 35 Shinanomachi, Shinjukuku, Tokyo, 160 
The response to treatment was assessed according to three indicators, specifically, clinical progress, sputum culture results, and radiographic responses. Patients were considered cured when satisfactory clinical progress and radiographic improvement were accompanied by persistently negative sputum cultures. The disease was regarded as progressive when there was clinical and radiographic deterioration with positive sputum cultures.

\section{Results}

\section{Case reports}

Case 1. A 61-year-old man complained of fever 9 months after gastrectomy. A chest X-ray obtained on June 30, 1990 showed an infiltrative shadow in the left upper lobe (Fig. 1). Acid-fast organisms were seen in his sputum. Multiple isolates were obtained from sputum and bronchial washing specimens. These isolates consisted of $100-500$ colonies. $M$. xenopi was identified on the basis of its microbiological characteristics. Yellow-pigmented colonies appeared after incubation at either $37^{\circ} \mathrm{C}$ or $48^{\circ} \mathrm{C}$ for 8 weeks. The organisms did not grow on Ogawa egg medium in an aerobic condition at $28^{\circ} \mathrm{C}$. The organisms showed several characteristics which allowed differentiation from other slowly growing mycobacteria of Runyon's Group II and III; negative photochromogenicity; niacin not produced; nitrate reduced, Tween 80 not hydrolyzed after 10 days; arylsulfatase positive after 3 days; susceptible to HA ( 0.5 $\mathrm{mg} / \mathrm{ml})$; resistant to para-nitrobenzoic acid $(0.5 \mathrm{mg} / \mathrm{ml})$; susceptible to ethambutol $(5 \mu \mathrm{g} / \mathrm{ml})$. The isolates were confirmed to be $M$. xenopi by the DDH method. Initial isolates from this patient were sensitive to streptomycin $(20 \mu \mathrm{g} / \mathrm{ml})$, kanamycin $(25 \mu \mathrm{g} / \mathrm{ml})$, cycloserine $(20 \mu \mathrm{g} / \mathrm{ml})$ and emviomycin $(25 \mu \mathrm{g} /$ $\mathrm{ml})$. The bacilli were resistant to isoniazid $(0.1 \mu \mathrm{g} / \mathrm{ml})$, rifampicin $(10 \mu \mathrm{g} / \mathrm{ml})$, ethambutol $(2.5 \mu \mathrm{g} / \mathrm{ml})$ and para-aminosalicylic acid $(1 \mu \mathrm{g} / \mathrm{ml})$ but sensitive to isoniazid $(1 \mu \mathrm{g} / \mathrm{ml})$, rifampicin $(50 \mu \mathrm{g} / \mathrm{ml})$, ethambutol $(5 \mu \mathrm{g} / \mathrm{ml})$, and para-aminosalicylic acid $(10 \mu \mathrm{g} / \mathrm{ml})$.

The patient was treated with $300 \mathrm{mg}$ of isoniazid, $450 \mathrm{mg}$ of rifampicin and $750 \mathrm{mg}$ of ethambutol per day. Streptomycin and para-aminosalicylic acid could not be used due to adverse side effects. The fever decreased, but positive sputum cultures persisted. In December 1992, he was hospitalized with symptoms of productive cough and fever. His chest $\mathrm{X}$-ray showed a new infiltrative shadow with a cavity in the right upper lobe. He was treated with $300 \mathrm{mg}$ of isoniazid, $450 \mathrm{mg}$ of rifampicin, 2 $\mathrm{g}$ of kanamycin, $500 \mathrm{mg}$ of cycloserine and $400 \mathrm{mg}$ of clarithromycin per day. His fever lowered and he was discharged in March 1993. Sputum cultures became negative three months after the second chemotherapy. He is now clinically stable, having shown significant radiographic improvement and negative sputum cultures.

Case 2. A 54-year-old man, in whom M. tuberculosis had previously been diagnosed but was presently inactive, was admitted to our hospital in October 1992, complaining of productive cough and fever. A chest X-ray, obtained on October 24 , showed an infiltrative shadow with a cavity, which had

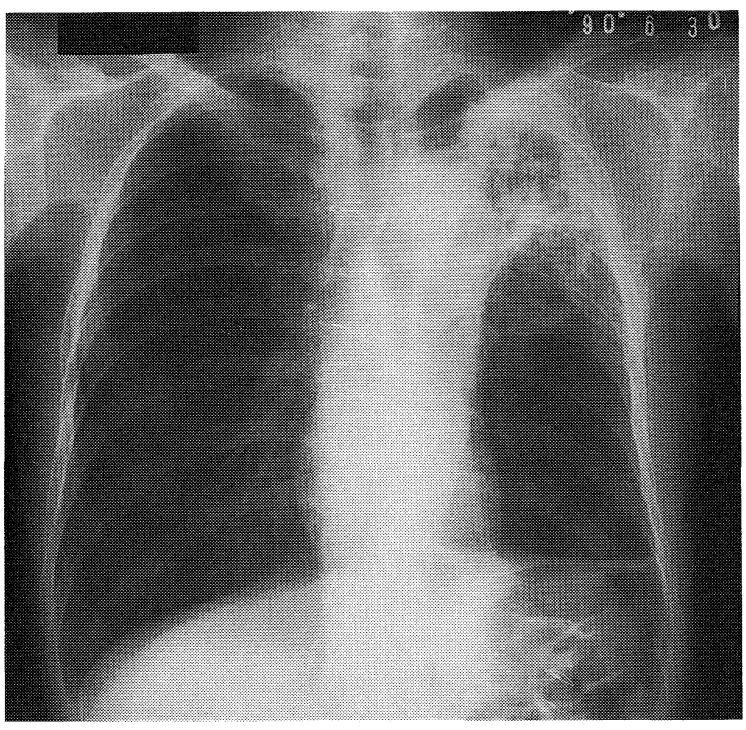

Fig. 1. A chest X-ray on June 30, 1990 showed an infiltrative shadow in the left upper lobe (Case 1).

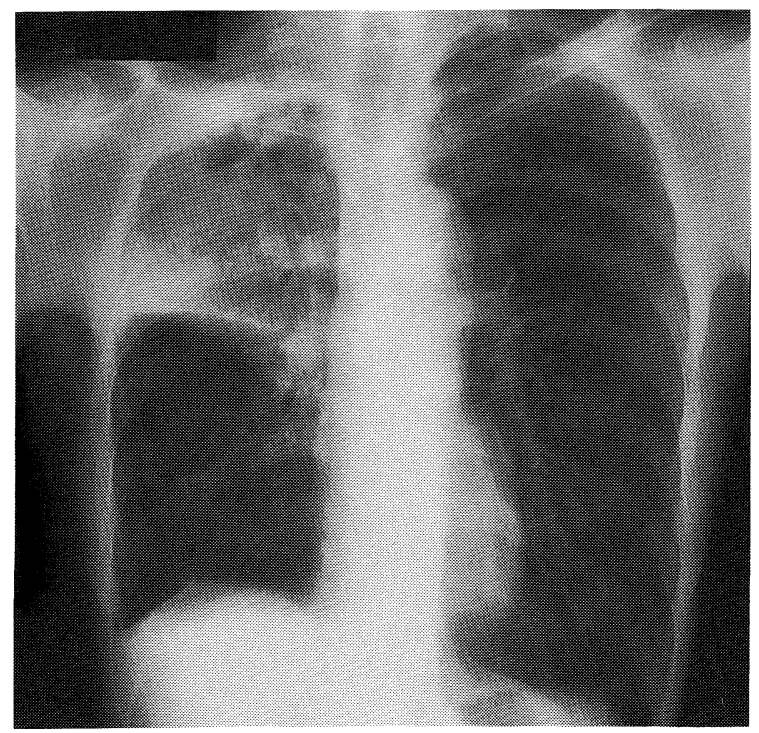

Fig. 2. A chest X-ray on October 24, 1992 showed a new infiltrative shadow with a cavity in the right upper lobe (Case 2).

not been present on October 2, in the right upper lobe (Fig. 2). Acid-fast organisms were seen in his sputum. Twelve isolates were obtained during a one-month period; 9 isolates from sputum, 2 from gastric juice and one from bronchial washing specimens. These isolates consisted of 10-30 colonies. $M$. xenopi was identified by culture. Yellow-pigmented colonies were obtained after incubation at either $37^{\circ} \mathrm{C}$ or $48^{\circ} \mathrm{C}$ for 8 weeks. The organisms did not grow at $28^{\circ} \mathrm{C}$. The strain showed negative photochromogenicity, did not produce niacin, reduced nitrate, and did not hydrolyze Tween 80 after 10 days. The isolate also revealed the following characteristics; resistance to 
HA $(0.5 \mathrm{mg} / \mathrm{ml})(-)$, resistance to para-nitrobenzoic acid $(0.5$ $\mathrm{mg} / \mathrm{ml})( \pm)$, resistance to ethambutol $(5 \mu \mathrm{g} / \mathrm{ml})(+)$, and branching filamentous extension on corn-meal-glycerol agar, resembling a "bird's nest". The isolates were confirmed to be $M$. xenopi by the DDH method. Isolates from sputum were susceptible to isoniazid $(0.1 \mu \mathrm{g} / \mathrm{ml})$, rifampicin $(10 \mu \mathrm{g} / \mathrm{ml})$, streptomycin $(20 \mu \mathrm{g} / \mathrm{ml})$ and kanamycin $(25 \mu \mathrm{g} / \mathrm{ml})$ but resistant to ethambutol $(5 \mu \mathrm{g} / \mathrm{ml})$. Transbronchial lung biopsy of the right upper lobe showed granulation tissue composed of epithelioid cells. Ziehl-Neelsen's and fluorescent stains failed to demonstrate the presence of mycobacteria.

The patient was treated with $300 \mathrm{mg}$ of isoniazid, $450 \mathrm{mg}$ of rifampicin and $750 \mathrm{mg}$ of streptomycin per day. The fever decreased within a week. After two months of therapy, sputum cultures became negative and chest $\mathrm{X}$-ray findings improved. He was discharged in December 1992. This is a case of rapidly progressive pulmonary infection caused by $M$. xenopi in a normal host. This patient's condition responded to antituberculosis drugs.

Clinical features and the mycobacterial data of 4 cases are shown in Table 1. All were middle-aged men. In case 1, lung infection due to M.xenopi occurred after gastrectomy. Two had a history of $M$. tuberculosis infection. Three had symptoms including cough, sputum and fever. Chest X-ray showed an infiltrative shadow with a cavity in a unilateral upper lobe in 3 of 4 cases. Isolates from three patients were identified not only on the basis of microbiological characteristics but also by the DDH method. This method requires no more than 3 or 4 hours to perform.

All isolates were susceptible to streptomycin and kanamycin. The disease was progressive in case 1 and a new infiltrative shadow appeared in the contralateral lobe during initial treatment with multiple drugs to which the organisms had shown borderline resistance on in vitro susceptibility tests. This patient showed a good response to the second course of chemotherapy, which was based on in vitro susceptibility.

\section{Discussion}

The typical patient with pulmonary infection caused by $M$.

Table 1. Clinical Manifestations

\begin{tabular}{|c|c|c|c|c|c|c|c|c|c|}
\hline Case & Age & Sex & $\begin{array}{l}\text { Pre-existing } \\
\text { disease }\end{array}$ & Symptom & $\begin{array}{l}\text { Chest } \\
\text { X-ray }\end{array}$ & Therapy & $\begin{array}{l}\text { Drug susceptibility/ } \\
\text { resistance }\end{array}$ & Outcome & Ref. \\
\hline 1 & 61 & M & Gastrectomy & $\begin{array}{l}\text { cough } \\
\text { sputum } \\
\text { fever }\end{array}$ & $\begin{array}{l}\text { LUL } \\
\text { RUL } \\
\text { cavity } \\
(+)\end{array}$ & $\begin{array}{l}\text { initial } \\
\text { INH,REP } \\
\text { EB } \\
\text { second } \\
\text { INH,RFP } \\
\text { KM, CS } \\
\text { clarythromycin }\end{array}$ & $\begin{array}{l}\text { S to } \\
\text { INH }(1 \gamma), \text { RFP }(50 \gamma), \\
\text { SM }(20 \gamma) \text {, KM }(25 \gamma), \\
\text { EB }(5 \gamma) \text {, TH }(50 \gamma), \text { PAS }(10 \gamma) \\
\text { EVM }(25 \gamma) \\
\text { R to } \\
\text { INH }(0.1 \gamma), \text { RFP }(10 \gamma) \text {, } \\
\text { EB }(2.5 \gamma) \text { TH }(25 \gamma), \\
\text { PAS }(1 \gamma), \text { PZA }(3000 \gamma)\end{array}$ & Cure & \\
\hline 2 & 54 & M & Tuberculosis & $\begin{array}{l}\text { cough } \\
\text { sputum } \\
\text { fever }\end{array}$ & $\begin{array}{l}\text { RUL } \\
\text { cavity } \\
(+)\end{array}$ & $\begin{array}{l}\text { INH,RFP } \\
\text { SM }\end{array}$ & $\begin{array}{l}\text { S to } \\
\text { INH }(0.1 \gamma), \operatorname{RFP}(10 \gamma), \\
\text { SM }(20 \gamma), \text { KM }(25 \gamma), \text { TH }(25 \gamma), \\
\text { PAS }(10 \gamma), \text { CS }(20 \gamma), \\
\text { EVM }(100 \gamma), \text { PZA }(3000 \gamma) \\
\text { R to } \\
\text { EB }(5 \gamma), \text { PAS }(1 \gamma), \\
\text { EVM }(25 \gamma), \text { PZA }(1000 \gamma)\end{array}$ & Cure & \\
\hline 3 & 63 & M & & $\begin{array}{l}\text { cough } \\
\text { sputum } \\
\text { fever }\end{array}$ & $\begin{array}{l}\text { LUL } \\
\text { cavity } \\
(+)\end{array}$ & & $\begin{array}{l}\text { S to } \\
\text { INH }(10 \gamma), \text { SM }(20 \gamma), \\
\text { KM }(100 \gamma), \text { TH }(40 \gamma), \\
\text { EVM }(100 \gamma) \\
\text { R to } \\
\text { INH }(0.1 \gamma), \text { RFP }(25 \gamma), \\
\text { EB }(5 \gamma), \text { PAS }(1 \gamma)\end{array}$ & Died & 11) \\
\hline 4 & 52 & M & Tuberculosis & & & & $\begin{array}{l}\text { S to } \\
\text { INH, SM, KM, TH } \\
\text { R to } \\
\text { RFP, EB }\end{array}$ & Cure & 12) \\
\hline
\end{tabular}

LUL: left upper lobe, RUL: right upper lobe, INH: isoniazid, RFP: rifampicin, SM: streptomycin, KM: kanamycin, EB: ethambutol, TH: ethionamide, PAS: para-aminosalicylic acid, CS: cycloserine, EVM: emviomycin, PZA: pyrazinamide, S: sensitive, R: resistant, $\gamma: \mu \mathrm{g} / \mathrm{ml}$, Ref: Reference number. 
xenopi is a middle-aged man with altered host defenses (5-9). Conditions predisposing to $M$. xenopi infection include previously treated pulmonary tuberculosis, chronic obstructive pulmonary disease, diabetes mellitus, alcoholism and the postoperative state (6-10). The infection usually follows a chronic indolent course. The present case 2 had previously been infected with $M$.tuberculosis. It was, however, atypical for a new infiltrative shadow with a cavity to appear within a couple of weeks in an otherwise healthy person.

The laboratory identification of $M$. xenopi requires 12 weeks because the bacterium grows slowly on solid media (13). Using the DDH method, the isolates from our patients were identified in less than 4 hours. This method of rapidly identifying mycobacteria offers significant advantages for clinicians who want to begin effective chemotherapy as quickly as possible.

Isolates from the four infected patients were uniformly susceptible in vitro to streptomycin and kanamycin. In case 2 , the response to chemotherapy correlated well with the results of susceptibility tests and a marked improvement was achieved. Previous reports have emphasized that $M$. xenopi is generally susceptible to most first-line antituberculosis agents $(8,9)$. In case 1 , however, the disease progressed during treatment with rifampicin, isoniazid and ethambutol. He showed satisfactory clinical and bacteriological responses after the regimen was changed, based on the results of susceptibility testing. Banks et al reported that there was a poor correlation between in vitro susceptibility results and clinical response (7). In the present two cases, pulmonary infection due to $M$. xenopi was successfully treated not with first-line drugs but with drugs to which the organisms had shown in vitro susceptibility. When a patient is diagnosed as having a pulmonary infection due to $M$. xenopi, based on the results of the DDH method, at least one month is required to test drug susceptibilities. Once the disease is diagnosed, it would seem reasonable to use a 3- or 4-drug combination, which might include isoniazid, rifampicin and either streptomycin or ethambutol, although the choice of drugs used in any individual patient must ultimately depend on the results of susceptibility testing for that isolate. It is likely that treatment should be continued for 18 to 24 months to eradicate the bacteria and prevent relapse.

The prevalence of $M$. xenopi varies geographically, being one of the most common nontuberculous mycobacteria isolated in France (5) and England (6, 7). In England, most isolates occur in coastal regions and around estuaries. Because of this distribution and a moderate degree of pathogenicity for fowl, it has been suggested that this organism may normally live as a commensal or pathogen in sea birds (6). In Japan, only 4 cases have been reported to date. It is difficult to identify isolates as
M.xenopi solely on the basis of microbiological characteristics, because this method requires at least 12 weeks and not all isolates have typical characteristics. Because the $M$. xenopi organism grows slowly and its clinical features resemble those of pulmonary tuberculosis, there may have been numerous $M$. xenopi infections which were not identified as such and were thus treated as "non-diagnosed" or "culture negative" $M$. tuberculosis infections. In addition, disease due to $M$. xenopi has been so rare and has received so little attention in Japan that many cases could have been misdiagnosed as other nontuberculous mycobacterial infections. In the future, however, more cases of pulmonary infection due to $M$. xenopi may be diagnosed in Japan as the DDH method can identify $90 \%$ of biochemically identifiable human pathogens within 3 or 4 hours (13).

\section{References}

1) Schwabacher $\mathrm{H}$. A strain of mycobacterium isolated from skin lesions of a cold-blooded animal, Xenopus laevis, and its relation to atypical acid fast bacilli occurring in man. J Hyg 57: 57, 1959.

2) Gross WM, Hawkins JE, Murphy DB. Origin and significance of Mycobacterium xenopi in clinical specimens. I. Water as a source of contamination. Bull Int Union Tuberc 51: 267, 1976.

3) Collins CH, Grange JM, Yates MD. Mycobacteria in water. J Appl Bacteriol 57: 193, 1984.

4) Grange JM, Yates MD. Infections caused by opportunist mycobacteria: a review. J R Soc Med 79: 226, 1986.

5) Parrot RG, Grosset JH. Post-surgical outcome of 57 patients with Mycobacterium xenopi pulmonary infection. Tubercle 69: 47, 1988.

6) Smith MJ, Citron KM. Clinical review of pulmonary disease caused by Mycobacterium xenopi. Thorax 38: 373, 1983.

7) Banks J, Hunter AM, Campbell IA, Jenkins PA, Smith AP. Pulmonary infection with Mycobacterium xenopi: review of treatment and response. Thorax 39: 376, 1984.

8) Simor AE, Salit IE, Vellend H. The role of Mycobacterium xenopi in human disease. Am Rev Respir Dis 129: 435, 1984.

9) Costrini AM, Mahler DA, Gross WM, Hawkins JE, Yesner R, D’Esopo ND. Clinical and roentgenographic features of nosocomial pulmonary disease due to Mycobacterium xenopi. Am Rev Respir Dis 123: 104, 1981.

10) Wickman K. Clinical significance of nontuberculous mycobacteria. Scand J Infect Dis 18: 337, 1986.

11) Tsukamura M, Sekine K, Yokota A, Kuze A, Shibata M, Sato K. Lung infection due to Mycobacterium xenopi: report of the first case in Japan. Microbiol Immunol 28: 123, 1984.

12) Sato A, Katagami N, Kusunoki S, Ezaki T. A case of pulmonary infection due to Mycobacterium xenopi. Kekkaku 68: 268, 1993 (Abstract) (in Japanese).

13) Kusunoki S, Ezaki T, Tamesada M, Hatanaka Y, Asano K, Hashimoto $Y$, Yabuuchi E. Application of colorimetric microdilution plate hybridization for rapid genetic identification of 22 Mycobacterium species. J Clin Microbiol 29: 1596, 1991.

14) Wolinsky E. Nontuberculous mycobacteria and associated diseases. Am Rev Respir Dis 119: 107, 1979. 